\title{
8. In-Flight Entertainment or the Emptying Process of Art in the Air
}

\author{
Christophe Génin
}

\begin{abstract}
Despite a series of material changes to the medium throughout its history, cinema has remained a "common immersive experience" insofar as it was based on the illusion of reality. However, the most important change is that this is no longer true: post-cinema, writes Christophe Génin, can be considered a defection of the original experience of watching movies. This situation has to do with social and economic transformations, implying the conversion of cultural industry to service to the person and a deep variation in the aesthetic experience, which Génin proposes to understand through an analysis of the experience of individual screens in aircraft. A confined space such as an aircraft seat isolates the individual to whom it is offered in a moment of "solipsism of caprice."
\end{abstract}

Keywords: Immersion, aircraft screen, solipsism

\section{What Do Post-art and Post-cinema Mean?}

Is there a post-movie era? And why would cinema have such an era? Compared to what baseline situation? Classically, the story was conceptualized retrospectively from an event or a man challenging a historical landmark with a before and an after: pre-history, pre-Socratic, pre-Colombian, preRaphaelite, etc. Today, since the success of postmodern thought by Lyotard, the formulations in post have multiplied and we think, no longer in terms of precursors, but in terms of successors: postmodernity, post-art, post-graffiti, and so on. So the prefix "pre" thought of history, according to the pattern of a latency that awaited its coming: the eldest Greek philosophers balked, but at last, Socrates arrived! Against this progressive and too often reductive

Chateau, D., and J. Moure. Post-cinema: Cinema in the Post-art Era. Amsterdam: Amsterdam University Press, 2020 DOI 10.5117/9789463727235_CHO8 
view, the prefix "post" conversely proposes a modular variation scheme. In this sense, post-cinema would not go beyond a deceased cinema but the alteration of an entity due to a change in parameter (for example, the passage of the digital film) from a module which would be the constant unit.

Therefore, to establish the possibility of a post-cinema requires an understanding of what cinema was. Let us start with a minimal definition: cinema is a popular spectacle based on illusionism thanks to a specific device. We will have objected that this definition is reductive and debatable. Of course, but it allows us to discern a practice. The cinematographic device was not that of the painter or the photographer, and its mode of exhibition differed from the theater, even if, today, by the digitization of all artistic practices, these distinctions are fading away.

We will try to understand this "after" of cinema based on its material conditions. However, we will not examine the material conditions of creation or production, particularly the transition from celluloid film to digital encoding, or the transition from traditional trickery (by theatrical retraction, by editing) to digital special effects. In fact, the history of cinema is comprised of these technological evolutions which, each time, were supposed to revolutionize it, or even complete it: the talkies, the color picture, the cinemascope, the Sensurround effect, the digitization. What will be recorded, how and using what method, for what restitution?

In our opinion, this changes only the modalities of performance of the cinema but not its aesthetic experience, in the sense that it remains faithful to its principle to be a show, that such a show be presented under a Barnum in a fairground festival, a reformed theater, a cinema, or a multiplex hall with giant screens and $3 \mathrm{D}$ vision. The very idea of a "huge" screen persists in saying what cinema proposes to be: an intensive and maximum sensory experience, from the entrance of the train in the station of La Ciotat on a flat screen to extreme surfing sessions on a geodesic dome. It will be objected that this is the perpetuation of Truffaut's 1954 "Papa's Cinema." What does it matter? We postulate that cinematograph, whether popular or not, documentary or fictional, is a common immersive experience: it is not only my personal experience of being sensitive and smart, my experience of an imminent meaning in terms of the senses, but even more a social experience of a common time, space and affect.

What does immersion mean? It is not only to be caught by synesthetic effects and an optical or acoustic illusion that would make us increase our presence in a purely fantasy world of fact, like virtual reality masks (which, in itself, is an oxymoron based on the perception of the aesthetic subject). It is a more radical consent, in principle, to accept a representation 
of the world as the presence of the world itself. When I watch RÉPARER LES VIVANTS (HEAL THE LIVING), ${ }^{1}$ I may know that the heart transplant scene is a silicone body altered by special effects. However, what matters is not the sensory-motor impact of the image on my perception, but the moral veracity of the human condition in the given situation.

For many years, cinema has been self-referencing its own technological transformation according to a principle of incorporation, the body of the receiver involved in the imaging, whether it be Tron (2010), Existenz (1999), The Matrix (1999), or Avatar (2009). We will not follow this baroque way of thinking because we propose that post-cinema be understood as a defection of this common immersive experience.

Thus, we will try to describe and understand the defection of cinema as art from its material reception conditions. Quite often "Dad's movie" was a poor man's cinema, a moment shared, commented on together, and felt together as seen in Cinema PARAdiso (1988). Conversely, the rich man's cinema was that of the private projection, solitary, as in SUNSET BOULEVARD (1950). Therefore, we will look for a current modular variation in the aesthetic experience of individual screens in aircraft. Today, with home cinema and, especially, with in-flight entertainment, the private, individualized projection has become the trend that ruins the aesthetic dimension (that of a koine aisthesis [Aristotle 1966, 425a27], or sensus communis).

But to think of post-cinema as one of the modalities of post-art, it is first necessary to understand what process art itself is likely to become obsolete. How does one define post-art? Literally speaking, it is what happens "after" (from Latin post) art. The whole question is to understand what this preposition "after" means, which is an indicator of ranking in time or space with various meanings. Indeed, the prefix "post" is polysemous.

- What follows is a phase that follows another, as in "post-doctorate" and "post-prandial" to indicate the transition to another state or situation that requires the first step as a sine qua non. In this sense, post-art would follow the art of which it would be a form of development or fulfillment. So, there would be no break, but rather continuity.

- Overtaking: that's the decisive meaning this time: from now on, we move on to something else and turn the page. For instance, we speak of "postoperative rehabilitation" which suggests that we wish to return to normal by solving a period of crisis or dysfunction, or of "post-graffiti" which implies that the period of street graffiti ends with their transfer to canvas and their sale in galleries, or of "postindustrial" which means a 
knowledge or digital economy. In this sense, post-art is the post-Oedipal stage of art: the resolution of an internal crisis.

- Reflexive side-by-side: the post-face or post-scriptum adds a separate element to the body text that can be a distant comment.

- The countertrend: postmodernity involves deconstructing great stories of modernity. In this sense, post has a critical value.

- Destruction: postmortem, post-abortum.

This prefix may seem contradictory since it may refer to continuity, change or destruction. However, a unit can be identified: post designates a variety of alterations that can evolve in positive intensity until deepening, or even to surpass oneself by oneself, or in negative intensity until withering.

\section{Is Post-art a Becoming of the Spirit?}

According to two different assessments, it seems as though the first overtaking of art as a spiritual activity was conceptualized by Hegel.

In the first place, there is an overtaking of art by reflexivity as it is exposed in Aesthetics. At first, this reflexivity can transcend creative activity: "Under all these relations art is and remains for us, in view of its highest determination, a thing of the past" (Hegel 1970, t.1, 25; my translation). In this sense, what makes art "past?" Henceforth, it is considered "for us," that is, subordinate to the "reflection" of "our judgment." It is this relationship to a judging and reflecting "we" that no longer makes art an immediate manifestation of the true, but an object for the science of the spirit. This reflexivity is then imminent to creative activity, what Hegel identifies in comedy as the end of art, in the double sense of Zweck: either a goal or a finish. Post-art would appear as the self-dissolution of art (sich aufheben). Indeed, Hegel identifies in the comedy a carnival inversion of the relations of power and authority; the master and the servant inverting their roles, turning in ridicule the absurdity of a power emptied of its effectiveness. Comedy is therefore the height of romantic art that expresses the freedom of the individual mind, the absolute no longer being an objective, transcendent and perennial principle, but subjectivity itself. ${ }^{2}$ It "finds its rest in itself, no longer unites itself to objectivity and real particularity, and becomes aware of the negative of this dissolution (Auflösung) in the humor of the

2 What Hegel also calls "the work of political art," the one in which the will of the slave is reflected infinitely in itself, emerging from slavery by the democracy that determines freedom on the mode of equality $(1963,196)$. 
comic" (1970, t.3, 572; my translation). If the comic shows the dissolution of the classical unity of objectivity and subjectivity, then, by transition, at the culminating point of this awareness in the buffoonery points to the dissolution of art (die Auflösung der Kunst) himself.

In fact, the comic exposes the self-destruction (die Selbstzerstörung) of this unity of the absolute and of the real existence (Dasein) and even annihilates (zernichten) the realization of the absolute truth through the free and contingent expression of subjective interests. The self-destruction of unity is the way in which the work is reflected. Indeed, in this dissolution of art in the ironic work, the subjectivity only remains self-confident and freed from any condition. This subjectivity remains self-assured in her self-censorship (sich aufheben) of any form of truth, unable to affirm any effectiveness (Wirklichkeit) of point of view in an artwork. By the way, art loses its substance, that is, "the eternal, the divine" (das Ewige, Gottliche) (1970, 573).

As he was able to reformulate it, Hegel thought that the art ends "in the dissolution of the objective content" in "the mood," i.e., in the irony of the artist who "is self-producing" $(2005,100)$. Why? Because the purpose of art is to express its content, the divine as the ideal of the spirit in itself. However, since its form is a "material sensitivity," it follows a "heterogeneity" of the form and content which does not allow it to express a spiritual truth in a lasting way, but only in an epoch of the development of the spirit by and for itself.

Hence, in the second place, there is a surpassing of art by another spiritual activity, either religion or philosophy. If one agrees to follow the Hegelian Encyclopedia, art would only be the embodied form of the spirit, placed in the matter's self, capable of being dissociated as pure spirit in religion, posing the spirit for oneself $(2005,40-46)$.

Hegel's thesis - "Art, for us, is a thing of the past" ("Bleibt die Kunst [...] für uns ein Vergangenes" (1970, t.1, 25; my translation) - announces that it is no longer the immediate form of the real since it is now mediated by aesthetic analysis, and is replaced by science as the modern form of truth, hence the historicity of the post. In the seventeenth century, art is still viewed by artists as a manifestation of the real, for example by Racine. But since the creation of the history of art and aesthetics in the eighteenth century, art has become mediated, subordinate to the interpretation of this reflexive "we." It is "for us," for the philosopher who irreversibly and thoughtfully inscribes the situation of art in a history and in an Encyclopedia of the Reason. Thus, it becomes a post-art, this "art according to philosophy" that Kosuth (1991, 153-167) thought prolongs and overcomes the Hegelian overtaking: by being 
conceptual and reflexive, art shows that it is not only a sensitive form of the intelligible (which would be cleared and interpreted by aesthetic science), but that it is also an intelligible form of an intelligibility which is imminent to the sensible faculty.

Post-art could thus be interpreted as the surpassing of art by itself, integrating in its production and conception a reflexive look, thus making self-reflexivity both the content and the form of the artwork. Could we also spot this in the cinema, and thus understand the post-cinema as its self-reflexivity?

It would be easy to find elements of reflexivity in various films. However, it seems to us that it would, in fact, be an error of interpretation of what this post can radically mean: not just a historical variation of an artistic expression but a change of paradigm. In other words, it does not seem to us that the "truth" of art is in its reflexive crisis, but rather in its material conditions which reveal the modalities of its efficiency.

Hegel's spiritualist interpretation obscures the role of tools and machines in the production of works of the mind: lifting machines for architecture (of which Vitruvius speaks in De Architectura), foundry for sculpture. There are also planers and saws for musical instruments, hangers and machinery in the theater, looms for tapestry, etc. There is a whole substrate of engineering necessary for the production of the works. Music is nothing without musical interpretation, itself linked to the invoice of instruments (Stradivarius, Steinweg), as the choice of a specific lens conditions a rhetoric or an aesthetic of the image.

Thus, in another materialistic sense, that is to say, taking into account the material conditions of the production of works as artistic genres (finance, machines, labor forces), post-art begins with the abandonment of a formal and aristocratic system of fine arts and may appear with new devices combining mechanics and chemistry. In 1839, photography, resulting from the research of the engineers, Niépce and Chevalier, and from the improvements of the painter, Daguerre, is presented by Arago before the Academies of Sciences and Fine Arts combined, thus overcoming the age-old division between the brain and the heart.

\section{Fragmentation of the Common Aesthetic Experience}

Based on which materialistic criteria do we move into this era of post? Post-cinema would begin with the gradual disappearance of this collective aesthetic experience: with the drive-in or open-air cinema-park 
which appeared in 1915 but which was formalized in 1933 by Richard M. Hollingshead in New Jersey. Here, a car park replaces the room, and the spectators remain in their cars to watch the movie like a family in a lounge with drinks and snacks. Nevertheless, the drive-in presented a double type of common experience: that of the family unit which found itself in the car, and that of amateurs, forming a kind of sociability at a distance of mutual interpellations, generation, as seen in AMERICAN GRAFFITI. ${ }^{3}$

To try and understand one of the current dimensions of post-cinema, let us start with the uses and a personal trivial aesthetic experience. I'm on a plane to a distant destination. I'm in economy class with some of the other passengers. To pass the time, the company no longer distributes newspapers, but installs individual screens at the back of each seat, facing each passenger. This screen fulfills two main types of functions:

- on the serious side, it provides information on safety and flight path; it transmits the announcements of the commander or cabin chief; it sometimes allows one to geo-locate certain data to anticipate one's stay; - on the entertainment side, it offers music or games, documentaries or movies.

I am caught here in the ancient dichotomy between the difficult matter and the pleasant, easy stuff, between the deep and the frivolous, between the presentation of the real and the expression of the imaginary, between information and fiction.

This individual touch screen or remote control brings everything back to entertainment: it's an IFE, an in-flight entertainment. The crew is no longer there to slip me a good word, to offer me a reading, to keep me company, because everything is delegated to the skimmer automaton which becomes almost my only vis-à-vis during the flight. The human being is being lost to electronic circuits. So, everything is considered "entertaining," whether it's a documentary or a children's cartoon, an author's film, or a block buster. Consequently, the worldwide cultural industries equalize every production into product designed in the light of personal leisure, without worrying about the spiritual value of a work. Proceeding according to a simple principle of multiple choices with induced logical trees, I can find quite quickly - when the screen works! - enough to kill my boredom, because the presupposition of such an automaton is that you become bored on an airplane. Unlike the train, where I can talk to my neighbor, go for a walk, change my mind at the bar car, go down to the platform to smoke a cigarette, watch the cows go by, read the newspaper or a station novel, it is readily accepted that aircraft are 
a source of boredom, stress and even anguish. As a third-class passenger, I am confined to a small space where everything is narrow, crammed in a tiny airplane seat, with no space for my legs, where I bump all over the hallway, where the offset porthole, small and distant, barely allows me to see the flow of clouds, it is necessary to divert my attention with a flow of images ad libitum. On long haul, I can only enjoy two square meters of relaxation space near the toilets with about ten other people.

This inert screen quickly becomes my travel assistant and my bored companion. Depending on caprice, I can zap the different menus before I find something to satisfy my mood. I can enjoy a freedom of indifference, all choices being equivalent to me, being the supposed master of the unfolded menu even when it is determined by commercial struggles between companies to place their cultural products. But I have the illusion of this freedom of indifference because - all tastes being in nature (or rather in cultures) - the range of offers exhaust human diversity: films of Blacks, Yellows, Whites, American or European-style comedy, thrillers and science fiction, action movies and war films, passing romances and kitsch love stories, Big Show productions or more intimate films, translated films or DVDs, etc. Multicultural, multi-ethnic, multigendered, the programming presented by the menu is the exact homothetic of globalized diversity. Or, more precisely, given the modest size of the screen, it is the miniaturization thereof: this screen is intended to be a representative summary of the planetary diversity in a colorful juxtaposition.

This catalogue of films is, in fact, a taxonomy of humanity - a taxonomy made, not from spiritual hopes or civilizational eras, but from behavioral frequencies reduced to consumables. I'm not a Western Christian, but a fan of crime fiction. There are categories of cinema like families of aromas in wine: we no longer talk about a soil (Japanese cinema or Chignin) or connoisseurs (in Turkish New Wave or in grape Jacquère), but individual preferences which can be classified statistically (SF or fruity taste). Taste no longer poses a tension between personal satisfaction and common sense. Rather, it is a quantifiable, predictable, exploitable frequency. Culture is no longer shared by common habits, times and meeting places dedicated to an identical passion. Instead, it is a series of pre-established silos based on mass data analyses. Even though the aircraft is, as a monospace craft, a shared public space (except the cockpit), everything is done to fragment it by means of class separations that reintroduce social segregation. And within the same class, everything is done to bring the individual back to/ on himself through the personal television screen (personal television or PTV), in fact, a multimedia monitor. Thus, there is an inverse movement 
between these aesthetic aggregations which order groups of preferences and these social partitions which reject individual differences.

My inquisitorial finger oscillates from music to anime, from the documentary on the Galapagos to a kung fu movie, and from the umpteenth remake of Planet OF THE APES to a French thriller. This menu is not a repertoire of cinema-club that would present me with a selection of the great classics, of the good values of the universal culture, as thought by UNESCO. Rather, it is a platform of bulk products, which presupposes in the individual user a right to cultural heterogeneity, to "dissonance" to use a Bernard Lahire's concept (2004). After all, Sartre (1990) loved THE MARK OF Zorro, and Deleuze enjoyed the French pop singer, Claude François. ${ }^{4}$ This IFE produces a cultural patchwork where everything is equally legitimate, where no pleasure might be guilty.

I make my decision about an episode of STAR WARS that I missed in the theater. Good choice: I fill a gap, and if I doze along the way, I would lose nothing in terms of understanding the plot. I launch the film. I plug in my headphones and try to focus on the 11-inch screen, but the intergalactic dimension doesn't lend itself to this handkerchief size ... Quickly, the Jedi figurines appear to me as plastic soldiers of my childhood, and I have passed the age of childhood ... My neighbor laughs at an American show that looks very silly, but which apparently gives him great pleasure. My more inspired neighbor breathes deeply through a yoga documentary in the "well-being" section and avidly watches a filiform yogi woman whom she may be hoping to resemble.

All these individuals carried by the same vehicle and going to the same destination on the same trajectory are atomized by this IFE. Each screen is a solo universe. All these egos are not consciences with which I could enter into a dialogue, but floating and separated imaginaries as an random and discontinuous stream. The time of a flight, I myself am only a series of accidental disruptions. Where is the art in such choices and capricious consumption? If art was, among other possible definitions, a requalification and existence, and a recollection of meaning, where does one find it in this dissipation? If art carries myth as a founding narrative of common life, how does this IFE make this myth possible? Certainly, I can think that all these entertaining films are many variations on universal myths, but they do not operate - as far as my intuition is admissible - as a federator of humanities. Like a spiritual partition, this IFE surrounds each passenger in

4 Cf., Claude François, L'Ombre au tableau, dir. Karl Zéro and Daisy D'Errata, Arte TV, 2017; quotation or L'AbÉcÉDAIRE DE GILLES DELEUZE at 50'. 
its personalized imagination with a singularized screen of flight time. Just as it was considered rude to read over another passenger's shoulder on a bus or in a metropolitan, it is inappropriate to look at my neighbor's screen. And these are just separated screens without any common framework. So screen is well named: this projection of your intimate imagination is an obstacle to Others' Intrusion.

Standing up in my chair, I look down the corridors of the plane and observe dozens of humans, each immersed in a particular screen with different lights and figures, like so many independent alveoli. It's no longer an aircraft fuselage, but a control room with a hundred disparate monitors. Supervising this humanity confronted with the fruit of its choices, choices anticipated, in fact, by probabilities, I picture myself as the Architect of THE MATRIX, showing Neo the screens of its indefinite variations. What is personal and decisive in affirming a taste for one category of works rather than another? Can I consider myself in a case of "spectator freedom" (Elder 2008, 168-192) because I would produce the conception of my perception? What am I in a giant screen room, concave, with a sensurround sound! What am I in full immersion in the film? Why am I standing in front of an electronic skylight?

In other words, where is the experience of art in this situation? Should I consider that it is only accidental, casual and that in this sense, it does not alienate the cinema, the films I can see? Conversely, should I think that the very idea of including films in this type of visual distribution shows that cinema is outdated, and that there are only audiovisual productions designed to be distributed on variable, modular and segmented carriers? One might think that such an alternative is artificial, with artistic productions and aesthetic experiences being as multiple and diverse as contingent truths.

The proliferation of screens is certainly not new, nor is it specific to post-cinema. It seems to appear even with the cinema itself. But there was the convergence of looks toward a same screen (whether single or multiple), and not the current divergence of looks toward a personalized and exclusive screen. Better still, to optimize the weight of the aircraft, and therefore the consumption of kerosene, the French company, Thalès, works on a wide screen inlaid in the back of the previous chair, or plans to soon replace these tablets embedded in the seats with an online streaming service on the plane from one's personal device.

Is it still cinema that I am watching when there is anymore show, that is to say, the polarization of human diversity toward the same stage in a common experience? Is it a cultural product? It is an entertaining product designed on a global scale, which identifies the elements of diversity and finds their 
logical equivalents. Therefore, it is not an author who makes sense through images, but a marketable scopic desire which is satisfied by approaching visual values, whether it be the nature or genre of the work/product.

\section{Where Is the Cinema?}

The question is not "what is cinema?" but, as Francesco Casetti notes, "where is it?" (2016). In other words, the question of recognition and acknowledgment is secondary to that of carriers and media. The question is complicated. Let's assume that the cinema projected by this IFE is an art of pleasure; so, where is the post-cinema?

Regarding this IFE, can I speak of an Entkunstung of cinema, of an "emptying process" or "desertification" (following Lacoue-Labarthe's translation [see 1994, 131-141, 2015]), in the sense that Adorno could theorize this in the Ästhetische Theorie (1970)? This seems too restrictive to us because the problem lies in the relationship between industry (including entertainment) and capitalist dynamics.

Contrary to what Adorno and Eisler said in the 196os, the mass culture of film and, particularly, film music, has not liquidated individuality (1969). In fact, massification is not consubstantial to the capitalist market which can produce large profits on small volumes with very high added value (luxury). The mercantile issue is that of sales and profit volumes. Massification was, in fact, a phase of capitalism which produced large-scale standardized products to segmented and cadenced production (Fordism), and a certain cinema corresponded to this format and formatting in the USA with Hollywood, in Germany with the UFA, in Italy with Cinecittà and in Asia with Bollywood and Hong-Kong. The fact that cinema has required industrial production since its beginnings, especially with the industrialists who were the Lumière brothers, does not mean that it is reduced to that, much less that it is the last word of show business.

For many years now, the search for capital value has been based on the customization of services. And cinema is no exception. The entertainment industry has converted to service to the person, especially thanks to the Internet, which allows traceability and exhaustive real-time analysis of the requests of each viewer/consumer to define a singular profile, through the analysis of the "favorites" and the recurring choices. The aesthetic experience disappears like that of common sense to become anyone's capriccio.

Is this emptying process a death of art, or its kitsch-becoming? Before producing a tragic reading of contemporary alienation (the substitution 
of the performance hall by the personal tablet), let us try to understand entertainment.

How should we think about entertainment? In French, we translate "divertissement" as "amusement" which corresponds with one of the senses of "to entertain": to amuse. In French, this connotation has been pejorative for a long time; the anathema launched by Georges Duhamel ${ }^{5}$ against cinema or the dichotomy recalled by Bernard Lahire between "culture" and "entertainment" $(2004,78)$ bear witness. In fact, to entertain is a sign of hospitality. "To entertain" comes from the French "entretenir" which, around the fifteenth century, meant to maintain good condition and show hospitality, and from there to welcome and put one's guests at ease with a good word, a good dinner, a party or a show. So, there is nothing pejorative or blameworthy about it. A singer who sings Schubert Lieder on a social evening is entertaining. A hotel pianist who plays well-known pieces of classical music, jazz or variety (oldies but goldies standards) will be an entertainer, a showman who ensures the well-being of guests. Thus, entertainment is the art of welcoming people into good society; it is an art in the sense that it takes sensitivity and resources to listen to others and satisfy their tastes.

The fact that IFE is entertainment is therefore not a problem but responds well to its very principle: to welcome passengers in a confined (often frightening) space in order to put them at ease and make them happy by satisfying their tastes, either by means of drinks or the catalogue of videos. This IFE would then fall under what Kant (1990) called "the leisure arts" (die angenehme Künste), those arts that are only for pleasure (Genuss) by a representation attached to a cheerful sensation, which would promote a sociable mood. However, why is there a sociability here, since, on the contrary, all social bonds are broken by such a solipsism of caprice? Does this materialistic interpretation of post-cinema consist of taking note of a lack of spirit?

On the one hand, this type of device breaks the time of the cinema, which is made of duration. The common immersion in the flow of the film makes us lose our sense of time or, on the contrary, in case of boredom, gives us the feeling that there are "lengths," the notion that the time of the film is no longer the time of my aesthetic experience. Similarly, the screen space is

5 “C'est un divertissement d'ilotes, un passe-temps d'illettrés, de créatures misérables, ahuries par leur besogne et leurs soucis. C'est, savamment empoisonnée, la nourriture d'une multitude que les Puissances de Moloch ont jugée, condamnée et qu'elles achèvent d'avilir [...] Le cinéma parfois m'a diverti, parfois même ému; jamais il ne m’a demandé de me surpasser. Ce n'est pas un art, ce n'est pas l'art" (1930). 
above the intervention of the spectators. Thus, the duration is homogeneous and continuous, and the immersive space is given, one being that I intend to contemplate.

On the other hand, the post-cinema breaks this paradigm of duration and pure reception. This pure reception is the reason why we live in duration. Everyone is in the discontinuous time of his or her choices and jumps, and the touch screen is a space on which I can intervene (rewind, fast-forward, stand-by, etc.), being then actor of the current viewing.

Should we stick to this binary reading: change of space and, especially, of time, continuous time and duration versus broken time, and social time versus solo time?

We don't think so. Indeed, I am not an autistic addict to my screen, to the extent that I can, precisely because of this manipulation which is always possible, leave the show to seek better satisfaction or to direct myself to a loved one to communicate my feeling about what I have just seen. In other words, the device most probably conditions the reception of the work, but it does not condition either the aesthetic judgment or the very idea of a communicability of the aesthetic experience.

Even if I see a film through a virtual-reality headset, alone and totally captivated by the illusionism of this new machine, I seek to share this vertigo and to make this fascinating view a common experience that everyone can repeat for him- or herself but with the intention of a joyful communicability.

In other words, the "post" horizon of post-cinema consists of producing a reverse of the modality of reception, but keeps from cinema the finality: the life of the soul, even though it would begin with entertainment and a so-called leisure arts.

If post-cinema expresses a survival of the cinema beyond all its changes of production tools and modes of reception, then its place can only be that immaterial communicability of feeling (with a dual sense of emotion and judgment) which, beyond all kinds of determinations, gives the human being his or her freedom of appreciation.

\section{References and Further Reading}

Adorno, Theodor, W. 1970. Ästhetische Theorie. Frankfurt: Suhrkamp Verlag. Adorno, Theodor, W., and Hanns Eisler. 1969. Komposition für den Film. München:

Rogner \& Bernhard.

—. 1972. Musique de cinéma. Translated by J-P. Hammer. Paris: L'Arche.

Aristotle. 1966. Péri psychès. De l'âme. Paris: Les Belles Lettres. 
Casetti, Francesco. 2016. "The Relocation of Cinema." In Post-Cinema: Theorizing 21st-Century Film, edited by Shane Denson and Julia Leyda. Falmer: Reframe Books. http://reframe.sussex.ac.uk/post-cinema/5-1-casetti/.

Duhamel, Georges. 1930. Scènes de la vie future. Paris: Mercure de France.

Elder, R. Bruce. 2008. "Multiple Screens, Spectatorial Freedom and the Conception of Production.” In Esthétique des arts médiatiques. Prolifération des écrans, edited by Louise Poissant and Pierre Tremblay. Québec: Presses de l'Université du Québec. Hegel, Georg Wilhelm Friedrich. (1837) 1963. Leçons sur la philosophie de l'histoire. Translated by J. Gibelin. Paris: Vrin.

—.1970. Vorlesungen über die Ästhetik. Frankfurt: Suhrkamp Verlag. —.2005. Esthétique. Cahier de notes inédit de Victor Cousin. Paris: Vrin.

Kant, Immanuel. (1790) 1990. Kritik der Urteilskraft. Hamburg: Felix Meiner Verlag. Kossuth, Joseph. 1991. "Within the Context: Modernism and Critical Practice." In Art After Philosophy and After. Cambridge: MIT Press.

Lacoue-Labarthe, Philippe. 1994. "Remarque sur Adorno et le jazz: D’un désart obscur." Rue Descartes (Modernités esthétiques), no. 10 (June).

- 2015. Pour n'en pas finir: Ecrits sur la musique. Paris: Christian Bourgois Editeur. Lahire, Bernard. 2004. La culture des individus. Dissonances culturelles et distinction de soi. Paris: La Découverte.

Sartre, Jean-Paul. 1990. Écrits de Jeunesse. Paris: Gallimard.

\section{About the Author}

Christophe Génin is Professor of Philosophy of Art and Culture Studies at the Panhéon-Sorbonne University, Paris 1. His research focuses on contemporary transformations of cultural representations, in particular on emerging and popular cultures, such as street art, kitsch, or cultural tourism. He addresses issues of interculturality or multiculturality as examples of a crisis of traditional or inherited values or norms of judgment. He is the author of numerous books on aesthetics and philosophy, such as Réflexions de l'art (1998) and Kitsch dans l'âme (2010). He has also edited several collective works such as Images et esthétique (2007) and Juger l'art? (2009). 